\title{
Motivation Path between the Difficulties and Attitudes of Using the E-Learning Systems in the Jordanian Universities: Aajloun University as a Case Study
}

\author{
https://doi.org/10.3991/ijet.v14i19.10551 \\ Ghazi Shakah $^{(凶)}$, Ali. T. Al-Oqaily, Fadi Alqudah \\ Ajloun National University (ANU), Ajloun, Jordan \\ g. shakaheanu.edu.jo
}

\begin{abstract}
E-learning system offer many benefits for the universities such as reduce physical expenses of learning, improve the management of learning processes, and enhance the learning. There are many challenges faced by the utilizing of E-learning systems, and the most important challenges are: technical difficulties, services accessibility, awareness, interactivity, and security concerns. These challenges need to be resolved in order to motivate the students to use the E-learning system This study aims to identify the difficulties that effect on the motivation and attitudes of using the El-earning system by the university students. The Technology Acceptance Model (TAM) is adopted in this study to construct the proposed model. in the proposed model, three related variable levels is considered based on the past studies; the various E-learning difficulties in the level of external variables ( independent factor), The motivation (usefulness and ease of use) of use the E-learning system in the mediating level, and , and the attitudes toward using the E-learning system in the target level (dependent factor). Based on the constructed model, three research hypotheses are developed to test the relationship between the E-learning difficulties and attitudes toward the E-learning system through the motivation of using the E-learning system. The quantitative data collection using questionnaire is used to collect the study data from 154 students in Ajloun national university in Jordan. Ajloun University is selected as a case study of Jordanian universities due the unique experience of the students in using synchronized E-learning system called BigBlueButton. The questionnaire data were analyzed using AMOS tool in order to discover the direct and indirect paths between the study variables. The significant results show that there strong effects of the students motivation on the relationship between three E-learning difficulties and the attitudes toward the using of these systems. . the technical difficulties, services accessibility, and services interactivity should be avoided/ improved to enhance the motivation level of using the E-learning systems, and consequently enhance the attitudes toward the using of E-learning system by the students. The contribution of this study represented by fill the research limitation of apply synchronize E-learning system in the Jordanian universities. . This study gives the university important details about the features of success implementations of E-learning systems.
\end{abstract}

Keywords-E-learning systems, Difficulties, Motivation, Attitudes, Universities. 


\section{Introduction}

The first known implementation of the E-learning is obtained in 1960 by "University of Illinois". At that time, the teaching activities were conducted using computers inside the university campus [1]. In the last two decades, the universities are providing more attention in using the E-learning systems due to the gained benefits from them $[2,3,4]$. The researchers define the E-learning concepts as the using of technology equipments in the learning processes [4]. Lin [5] mentioned that the E-Learning is the utilizing of information technology in the learning processes through convert the traditional learning styles to modern styles. Hence, the teachers could innovate effective ways to deliver the learning materials in less time and efforts.

According to Som [6], there are four main approaches of the E-learning which are:

- Online E-learning that allows the online management of learning materials such as download/upload assignments, and provide quizzes

- Offline E-learning that provide the learning material based on various tools like the courses on Compact Disc (CD)

- Synchronized e-learning that provide real time communication between the lecturer and the student such as audio and video conversation

- Asynchronous e-learning, which is the non-real time communication between the lecturer and the students such as emails. This research focuses on the synchronized e-learning approach due to its powerful benefits in conduct the distance learning processes.

The synchronized or distance E-learning would provide many benefits for the education institution, lecturers, and students. Arkorful and Abaidoo [7] mentioned that through distance E-learning, the educational institution could save the physical costs of the learning processes, reduce the working stress inside the campus, and expand the capacity of the registered students. On the other hand, the lecturer can save the time and efforts in provide the learning material, and increase the learning productivity through conduct more learning tasks in less time. Furthermore, the students could receive the learning materials based on preferred learning styles (i.e. audio, video, images, and texts), reduce the time and efforts that required taking the full course time inside the campus, and using better interactivity tools to learn.

Despite the powerful benefits of the E-learning systems, The E-learning utilizing in the Arabic countries faces many limitations and difficulties such as the limit internet access and limit in technology equipments [8,9]. Another issue is the behavior of students toward the using of E-learning systems. The students may de-motivate of using the E-leaning systems due to many reasons such difficulties in using the Elearning systems, difficulties in own the technical equipments, weak awareness of the E-learning benefits, and privacy and security concerns $[9,10]$. These challenges present the importance of understand the required E-learning features, know the learning needs of the students, and provide the students with compelling E-learning skills.

Based on the above challenges, there are two important keys that could lead to the success of adopting the E-learning systems by the universities. The first success key is 
the selection of the E-learning system based on useful features. The second success key is motivating the students to use the E-learning systems through resolve the difficulties in using these systems. Therefore, the main aim of this study is to explore the students' motivation of using the E-learning system in the Jordanian universities based on selected case study of E-leaning systems.

\section{Theoretical Considerations}

This section presents the theoretical considerations that support the construction of the conceptual model in this study. In the context of learning quality, there are many theories support the utilizing of E-learning systems, and the most two important theories are constructivist and VARK theories.

The constructivist theory explains that the efficient learning processes should be constructed based on three elements; (1) expressing the idea through tangible the learning concepts based on methods such as figures and illustrations, (2) learning ideas through show the concepts in real actions in the world i.e. video or animation, and (3) judging ideas through provide new ideas and explore the problem solving i.e. tasks and assignments. Figure 1 illustrates the phases of constructivist theory. Aqda [11] mentioned that the effective E-learning systems allow the lecturers to adopt the constructivist learning processes. The E-learning systems provide fixable facilities to help the lecturer in provide learning processes based on the constructivist steps.

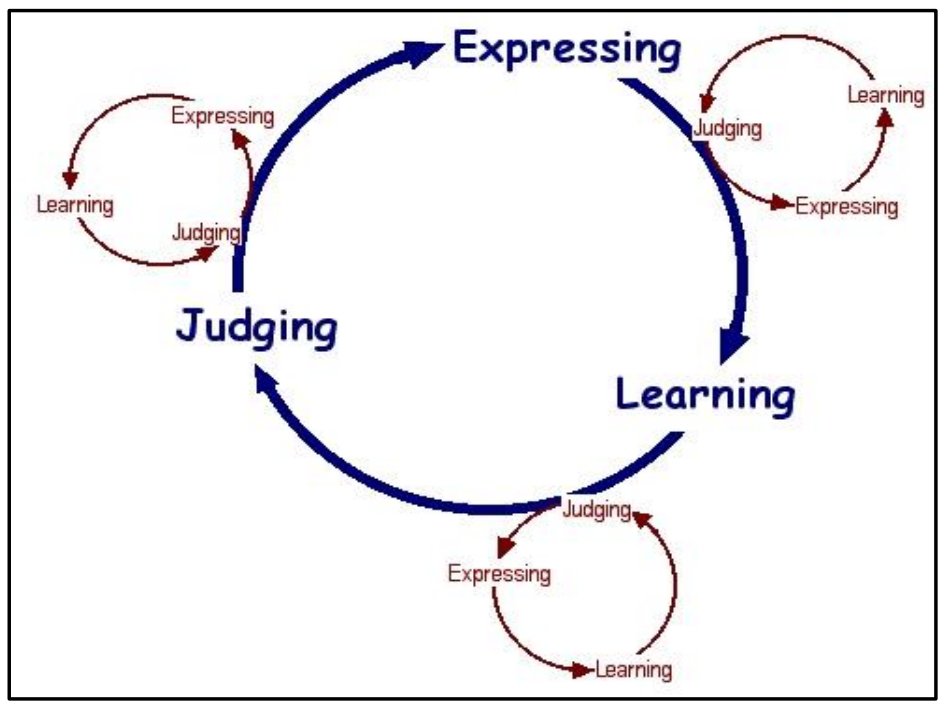

Fig. 1. Constructivist Phases

On the other hand, the VARK theory explains that the effective learning processes should be conducted based on various learning styles (Visual, Aural, Read/Write, and Kinesthetic) [12]. Hence, the students can accomplish the learning processes based on 
the preferred style(s). Figure 2 shows the VARK theory. The effective E-learning system able to deliver the learning materials based on various learning styles, whereby the students will enjoy the learning processes.

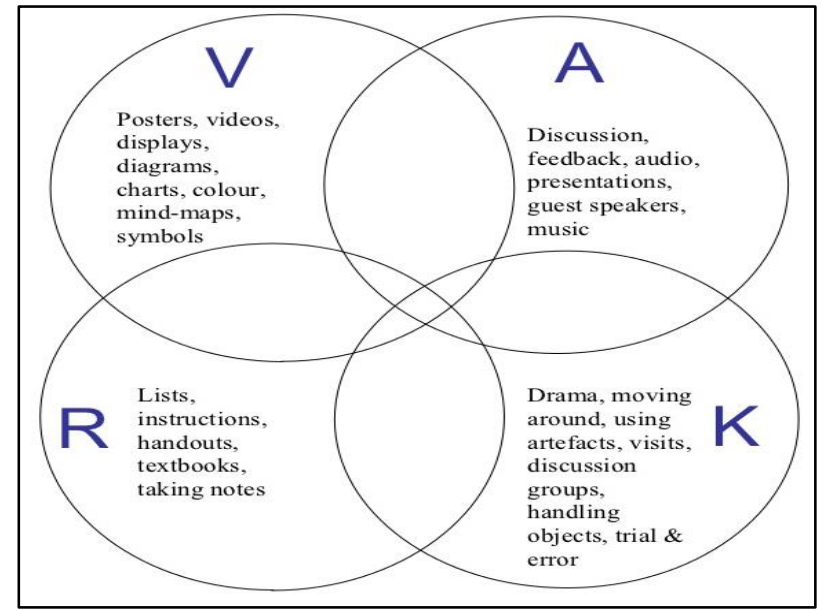

Fig. 2. Elements of VARK theory [12]

Although, the constructivist and VARK theories support the utilizing of the Elearning systems, the main concern of this study is exploring the students' motivation of using the E-learning system. The motivation of using the E-learning systems can be measured based on the technology acceptance models such as TAM model. In the 1970 s, the growth of information technology led organizations to adopt the systems rather than traditional methods (i.e. papers). However, there are many failures that occurred in the systems adoption. Thus, the researchers started to find many methods to ensure the success of the systems implementations. One of the most important reasons of the system adoption failure is the weakness of accepting the new technology instead of old systems due to many reasons such as the weakness of users' technology skills. In 1985, Fred Davis develops TAM as a proposed method to measure users' technology acceptance in order to evaluate the users' motivation of using the technology systems [13]. Davis [13] measured the technology acceptance by analyzing the motivation levels of using systems features and capabilities and evaluated the measurement through the actual use of the systems (as illustrates in Figure 3).

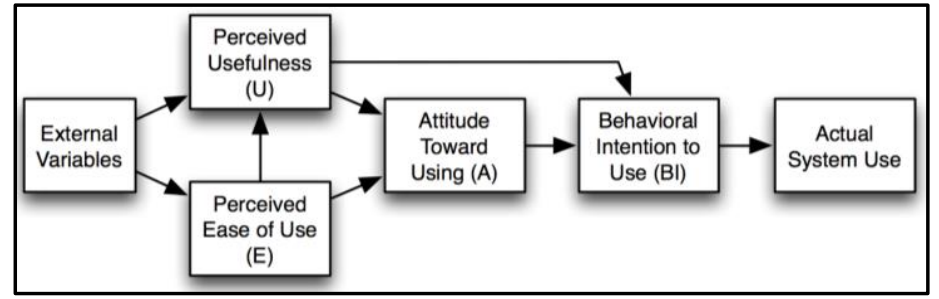

Fig. 3. TAM Structure [13] 
The core conceptual model of this study would be constructed based on the TAM model in the above Figure 3. The usefulness and the ease of use the E-learning system is supposed as mediating factors. The usefulness is "the degree to which an individual believes that using a particular system would enhance his or her job performance.”, while the ease of use is "the degree to which an individual believes that using a particular system would be free of physical and mental efforts" [14]. One the other hand, the attitudes toward the using of E-learning systems is considered as dependent factor. Moreover, the independent factors may any considerations those effects on the motivations of E-learning systems. The following explanations discuss the independent factors in this study.

Several works mentioned that the difficulties in own the technical features to use the E-learning system could de-motivate the students using of E-learning systems [15]. The more technical requirements increase the complexity of using the E-learning systems $[16,17]$. The technical features represented by many variables such as internet connectivity, internet availability, operating platforms, operating browsers, devices speed, devices capacity, and the devices supporting of deal with various data format $[16,17,18,19]$. Thus, the technical consideration of the E-learning systems is the important independent factor in this study.

The second important independent factor is the accessibility and availability of the E-learning services. Many studies discussed that the using of E-learning systems in anytime and from anywhere is important to motivate the using of these systems [20, $21,22,23]$. The difficulty in access the E-learning services in anytime increases the difficulty of use the system facilities wherever the students need. Also, the limitation in the availability of the E-learning services increases the difficulty of use the system whenever the students need.

Furthermore, many researchers have considered the students interactivity or motivation as a critical success factor in E-learning environments [16, 17, 18, 19]. The main concern here is that the students are not communicating face to face with their lecturers [20, 24]. The learning processes are conducted via the online technology facilities. Hence, the students could face challenges in use the E-learning services effectively and efficiently as they learn in real classes.

In Addition, several studies argued that the awareness is one of the most critical factors in the success of using the E-learning systems [25, 26, 27]. The students should aware of the benefits that could be gained from the using of E-learning systems. The low awareness level may de-motivate the using of the system, while the awareness level could improve the motivation of using the systems.

Lastly, many researchers take in account the privacy and security of the E-learning systems [28, 29, 30]. The online learning systems gather information between the students and lecturers via the online network. The students may have privacy and security concerns in using these systems. The students account may accesses illegally (low privacy), or attacked (low security). The low protection level of the students' data could de-motivate the using of E-learning systems. Therefore the security and privacy concern is important independent factor in this study.

Based on the above discussion and the structure of the TAM, the conceptual model and research hypotheses are constructed (Figure 4). The external or independent fac- 
tors in this study are the technical difficulties in using the E-learning systems, the difficulties in using the E-learning services, the interactivity difficulties, the awareness of E-learning benefits, and the concerns of the privacy and security features. There are two important mediating factors that belong to the E-learning motivation dimension, the usefulness and ease of use the E-learning systems. The dependent factor is represented by the attitudes toward the using of the E-learning systems.

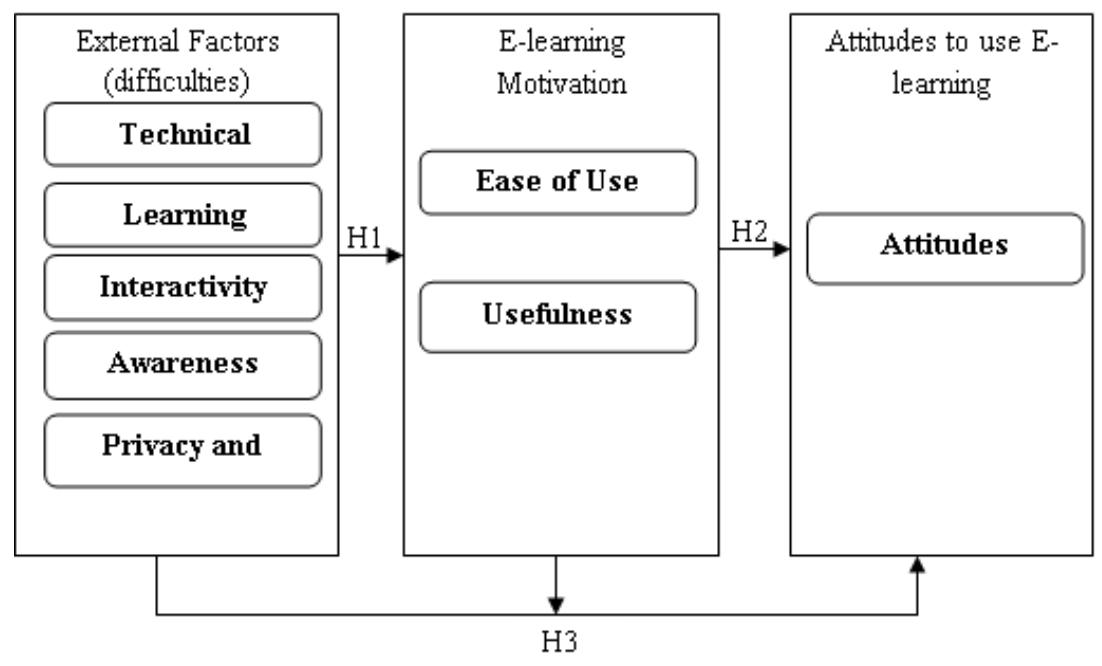

Fig. 4. Conceptual model and research Hypotheses

Based on the above Figure 4, there are three research hypotheses would be tested, and these hypotheses are as the following:

- H1 (+): The low difficulties in using the E-learning system have positive relation with the E-learning motivation.

- H2 (+): The high level of E-learning motivation effect positively on the attitudes toward the E-learning systems

- H3 (+): There is positive relationship between the low difficulties in using the Elearning system and the attitudes toward the using of E-learning system through the mediating impact of the student's motivation.

\section{Research Method}

This section present the method of this study included the data collection setting, techniques sample, population, and analysis methods. 


\subsection{Case study data collection}

This study collect quantitative data using questionnaire instrument due to usability of the questionnaire in collect data from large respondents in low time and efforts. The questionnaire was designed based on many sources such as Rodríguez-Ardura [1], Qureshi [31], and Davis et al [13]. The initiated questionnaire was reviewed by three experts in the E-learning domain, and the given comments are updated in order to finalize the last questionnaire draft.

The data of this study is collected in the end of the $1^{\text {st }}$ semester 2018/2019 from Ajloun university students as a case study of Jordanian universities. As mentioned in section 1.0, this study focuses on the synchronized approach of E-learning system. The selection of Ajloun University as case study is due to its students experience in using E-learning system called BigBlueButton. the university put efforts in utilize the E-learning systems in order to increase the competitive advantage of the learning processes. The university conducts many E-learning lectures using BigBlueButton in the $1^{\text {st }}$ semester 2018/2019. The BigBlueButton is considered as synchronized Elearning system, whereby the lecturers and students can obtain real time lecturers using many facilities like video conversation, audio and text chats, online explanation board, and upload/ download materials. Hence, the respondents have good idea about the questionnaire contents.

The total population of the case study is about 1700 students, and according to Yount [32], the minimum required sample rate based on this population is 5\% (85 students). However, to obtain the validity of the questionnaire, the data were collected from 154 students who study in Ajloun University. The questionnaire was distributed 200 students, but 46 responses were excluded due to invalid features (i.e. not complete answers). The response rate of the collected data is $77 \%$, which is very good response rate (i.e. the respondents care about the study idea).

- For effective data collection, there are many procedures are conducted:

- The questionnaire was translated to Arabic language (the mother language of the students)

- The questionnaire was distrusted using paper forms

- The research idea is explained very well to the respondents

- The questioner items are explained carefully

- The respondents take sufficient time to complete the questionnaire. the respondent answers collected based on 5-likert scale:

-1 for strongly disagree (SD)

-2 for Disagree (D)

-3 for Neutral $(\mathrm{N})$

-4 for Agree (A)

- 5 for Strongly Agree (SA)

5 -likert scale is more focused than lower scales and produce relative responses means more than high scales (Dawes, 2008). 
It is necessary to mention that the questionnaire was distributed based on the balance quota technique. The data were collected form students in balanced education levels $\left(1^{\text {st }}\right.$ study year, $2^{\text {nd }}$ study year, $3^{\text {rd }}$ study year, and $4^{\text {th }}$ study year $)$. On the other hand, the respondents are attending various E-learning courses of different education levels and precipices such as information technology courses, management information system, low, and mathematic courses.

\subsection{Measurement}

The scaled items in the questionnaire were selected from the existing appropriate literature on E-learning difficulties and motivation. Moreover, the questionnaire was evaluated by three experts in the E-learning domain. The questionnaire items were translated into the mother languages that used by the students.

In addition to the four demographic variables (age, E-learning experience, features of technology devices, and internet connection), the total of scaled items in the questionnaire is 38 items; 5 items represent the technical difficulties of the E-learning system. 4 items represent the difficulties of E-learning services, the interactivity difficulties consists of 4 items, the awareness difficulties consist of 4 items, the privacy and security concerns represented by 3 items, the E-learning usefulness consists of 7 items, the ease of use E-learning consists of 7 items, and the attitudes toward using the E-learning represented by 4 items. The 38 scaled items in the questionnaire would be helpful to measure the study constructs.

\subsection{Analysis methods}

In this study, Structured Equation Modeling (SEM) using AMOS software conducted to test the overall hypotheses due to the mediating structure of the theoretical model. SEM is a very general,and very powerful multivariate analysis technique. SEM is often used to assess unobservable 'latent' constructs. The links between constructs of a structural equation model may be estimated with independent regression equations or through more involved approaches [33]. In specifying pathways in a model, the modeler can posit two types of relationships:

- Free pathways, in which hypothesized causal (in fact counterfactual) relationships between variables are tested, and therefore are left 'free' to vary

- Relationships between variables that already have an estimated relationship, usually based on previous studies, which are 'fixed' in the model.

SEM includes confirmatory factor analysis, path analysis, partial least squares path analysis, LISREL and latent growth modeling. Thus, SEM will be effective to test the developed hypotheses in this research. 


\section{Results Discussion}

This section presents the results discussion including the demographic analysis, confirmatory Factor Analysis (CFA), descriptive Analysis, and the Structural Equation Model (SEM).

\subsection{Demographic analysis}

In order to ensure the usefulness of the collected responses, the respondents' characteristics are analyzed through four demographic variables; age, E-learning experiences, owning of technology devices, and internet connection. Table 1 summarizes the frequency analysis of the demographic data.

Table 1. Respondents' Demographic Data

\begin{tabular}{|l|l|c|c|}
\hline \multicolumn{1}{|c|}{ Variable } & \multicolumn{1}{|c|}{ Items } & Frequency & Percentage \\
\hline \multirow{4}{*}{ Age } & $20-23$ years & 108 & $70 \%$ \\
\cline { 2 - 4 } & $24-27$ years & 24 & $16 \%$ \\
\cline { 2 - 4 } & $28-31$ years & 14 & $9 \%$ \\
\cline { 2 - 4 } & $>31$ years & 8 & $5 \%$ \\
\hline \multirow{4}{*}{ E-learning Experience } & First time & 28 & $77 \%$ \\
\cline { 2 - 4 } & Medium experience & 8 & $18 \%$ \\
\cline { 2 - 4 } & High experience & 132 & $86 \%$ \\
\hline \multirow{2}{*}{$\begin{array}{l}\text { I own computer or mobile devices of } \\
\text { good features i.e. capacity }\end{array}$} & Yes & 22 & $14 \%$ \\
\cline { 2 - 4 } I have good internet connection & No & 134 & $87 \%$ \\
\cline { 2 - 4 } & Yes & 20 & $13 \%$ \\
\cline { 2 - 4 } & & & 5 \\
\hline
\end{tabular}

Based on the above Table 1, most of respondents' ages are between 20-23 years (70\% of all respondents), the respondents of age between 24-27 years represent $16 \%$ of the respondent's total, followed by $9 \%$ for the ages between $28-31$ years, then $5 \%$ for the age more than 30 years. These percentages matched with nature of respondents in this study (undergraduate students). The respondents' ages support this study due to the focusing on the undergraduate students when applying the E-learning systems in the universities. Regarding to the variables of E-learning experience, most respondents are use the E-learning system for the first time (77\% of all respondents). $18 \%$ of all respondents are have medium experience level in using the E-learning systems, while $5 \%$ of all respondents have high experience level in using the E-learning systems. The low experience level in using the E-learning systems indicates the importance of this study through analyzes the difficulties and motivation of using the Elearning systems by university students. The last two demographic variables (owning technology devices and internet connection) show that the major of respondents $(86 \%$ of the respondents) have sufficient computer and mobile devices to use the E-learning systems and $87 \%$ of all respondents have good internet connection to use the Elearning systems., the demographic data show that the respondents have valid characteristics to provide useful data in order to support this study. 


\subsection{Confirmatory factor analysis and descriptive analysis}

This section presents the Confirmatory Factor Analysis (CFA) in order to test the accuracy of the collected data (model fit). According to Hair [34], the data accuracy test focuses on the measurement of data scales based on the model construction. The collected data must integrate accurately with the study factors that compose the proposed model. The weak representation of the study factors through the collected data may lead to fail of the model construction. The CFA aims to measure several accuracy directions such as the fitness of the model factors, the factors reliability, and the relationships within the study factors. The CFA includes two important accuracy tests:

- The validity or factor loading test which aims to assure the interrelation between the items of the model dimensions. The validity could indicate if there is any strong connections between the responses to represent the model dimensions. According to Nunnally and Bernstein [35], the acceptance level of the factor loading (validity) should be more than 0.5

- The reliability based on Crombach Alpha (CA) test aims to assure that the repsones were not filled randomly by the respondents, and the accepted coefficient of the $\mathrm{CA}$ is $>0.7[35]$.

The CFA is conducted on three sub-models that involve the overall model in this study (38 scaled items). The first sub-model is the difficulties of using the E-learning system, which composed of five factors; Technical Difficulties (TD) of 5 items, Services Difficulties (SD) of 4 items, Interactivity Difficulties (ID) of 4 items, Awareness Difficulties (AD) of 4 items, and Privacy and Security (PS) of 3 items. The second sub-model is the motivation of using E-learning system that consists of two factors; Usefulness (UF) of 7 items, and Ease of use (EU) of 7 items. The third sub model is the attitudes toward using the E-learning (AT) which include the altitude factor of 4 items.

Figure 5 summarizes the CFA of the difficulties model, which includes five factors. Due to unacceptable factor loading $(<0.5)$, there are 2 items excluded from this model, and these items are TD5, and ID4. It is necessary to mention that the path retesting is failed in enhance the factor loading of the removed items. The entire 18 items in this model are records acceptable factor loading (> 0.5). Furthermore, the reliability test provides acceptable CA coefficients for the five factors in the difficulties model; 0.82 for TD factor, 0.91 for SD factor, 0.76 for ID factor, 0.88 for AD factor, and 0.93 for PS factor.

Based on the modified model, the model fit tests are conducted to assure the corresponding between the model data. The most important indices of model fit are RMSEA, GFI, AGFI, CFI, TLI, IFI, and $\chi 2 / \mathrm{df}$ (DeVellis, 2011). The GFI coefficient is 0.889 , whereby the acceptable cut value of the GFI should more than 0.8 (Hoyle, 1995). The cut value of the Adjusted GFI (AGFI) records 0.821, and regarding to Chau and $\mathrm{Hu}[36]$ this cut value is acceptable fit indicator (i.e. > 0.8). The acceptable value of the CFI, TLI, and IFI indices should be more than 0.9 [34, 37). All of these tests record acceptable fit values, the CFI coefficient 0.917 , the TLI coefficient is 0.946 , and the IFI coefficient 0.925 . The coefficient of RMSEA must below 0.1 [38]. 
The RMSEA test records 0.053 , which is acceptable coefficient that indicates the fitness among the model items. The results of all conducted tests are matched with the adequacy of $\mathrm{X} 2 / \mathrm{df}$ (2.418), which is below the cut value of 5. In summary, the modified CFA model for the E-learning difficulties is fit. Hence, the model data would be adopted for further SEM analysis such as research hypotheses.

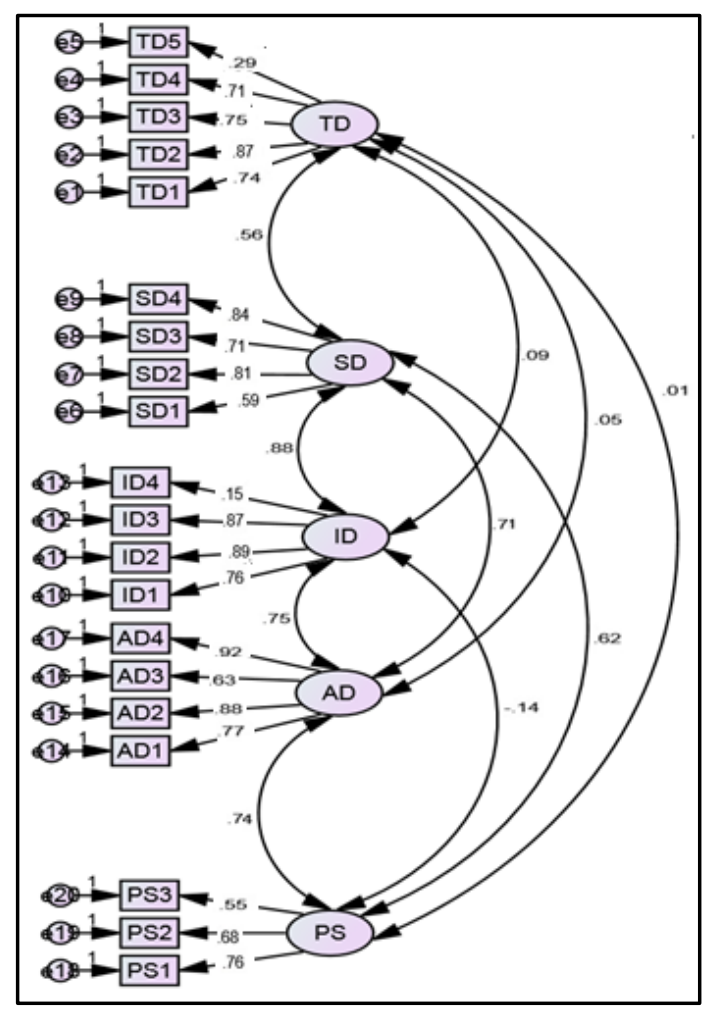

Fig. 5. CFA of Model of E-learning Difficulties

The above Figure 5 shows that there are significant relationships between various factors of E-learning difficulties; TD and SD (0.56), SD and ID (0.88), SD and AD (0.71), SD and PS (0.62), ID and AD (0.75) AD and PS (0.74). In other words, the technical and services difficulties are related in the using of E-learning system. The services difficulties are also related to with the interactivity, awareness, and security issues of the E-learning systems. Other relations are founded between the interactivity and awareness difficulties, and between the awareness and security issues of Elearning systems.

In order to provide clear discussion for E-learning difficulties model, the descriptive analysis is conducted based on the 18 items in the modified model (Figure 6). In total, the respondents are disagreeing that they face technical difficulties in using the E-learning systems such as the sufficient devices, internet connection, and network speed. In the context of the services difficulties, the respondents face some difficulties 
in the services of E-learning like the online problem in listening to the teachers voices (SD2). The respondents are not fully satisfied about the way of online material providing (SD1), and they may have difficulties in show and download/displayed synchronized material (SD4).

Furthermore, the respondents are not sure that the E-learning systems could provide interactive discussion. The respondents have difficulty in provide what they need from the teachers in the online classroom (ID1) and they find it difficult to in the online communication (ID2). Although, the E-learning systems equipped by interactive facilities such as voice and text chats, mostly theses facilities are disabled (ID3). In the context of the awareness and security factors, the respondents are disagreeing that these factors represent main difficulties in using the E-learning systems. The respondents see that they have good awareness of the gained benefits of the Elearning systems, and they don't see that the data privacy and security is critical issue in the E-leaning systems.

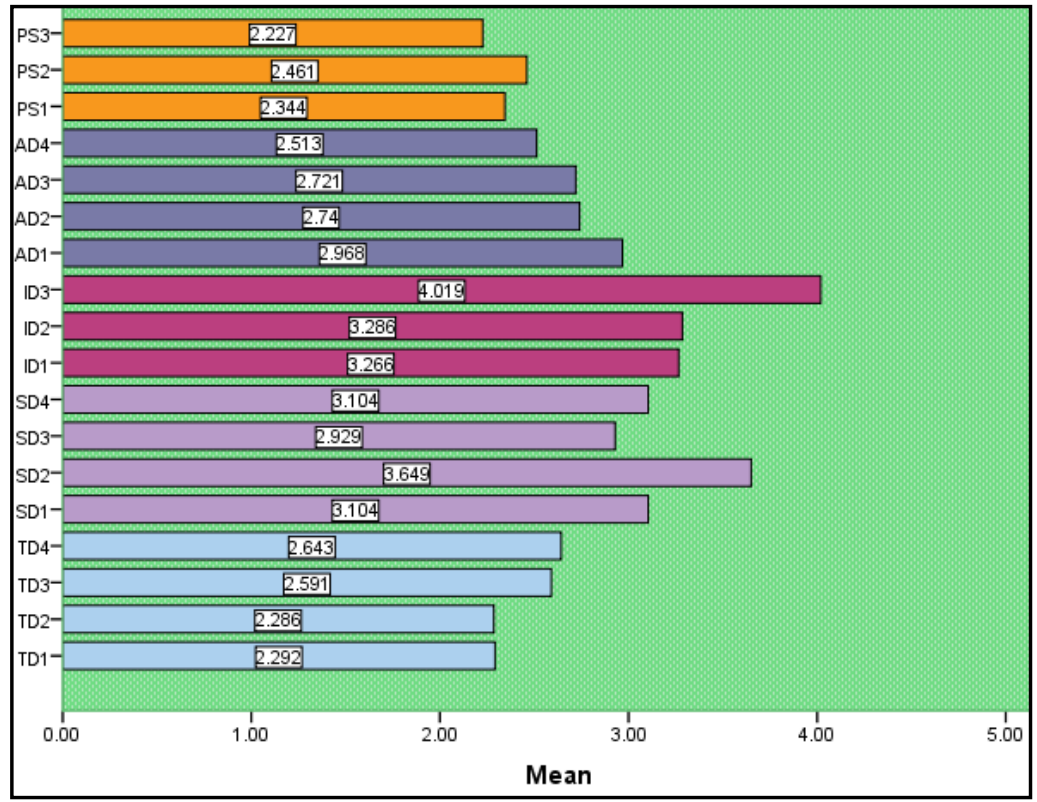

Fig. 6. Descriptive Analysis of E-learning difficulties

The CFA analyses are conducted on the second sub-model in this study, which is the motivation of using the E-learning systems. The motivation model includes two factors:

- The usefulness (UF) of using the E-learning systems

- The ease of use (EU) the E-learning systems. Figure 7 summarizes the CFA of the motivation model. 
There are 2 items which excluded from the EU factor due to un-acceptable factor loading $(<0.5)$, and these items are EU1, and EU3. Taking in account that the path retesting is failed in improve the validity of the EU1, and EU3. Based on the modified model of E-learning model-12 items-, the reliability test shows that the UF and EU factors are useful. the CA coefficients of the UF and EU are 0.93 and 0.84 respectively. Furthermore, the measurement indices show that the modified motivation model is fit. The GFI coefficient is 0.831 , the cut value of the AGFI is 0.844 , the CFI coefficient 0.924 , the TLI coefficient is 0.957 , and the IFI coefficient 0.939 . The RMSEA test records 0.068 , which is acceptable coefficient that indicates the fitness among the model items. The results of all conducted tests are matched with the adequacy of $\mathrm{X} 2 / \mathrm{df}$ (3.523), which is below the cut value of 5. Thus, the modified CFA model for the E-learning motivation is fit, and the data of this model can be used for further SEM analysis.

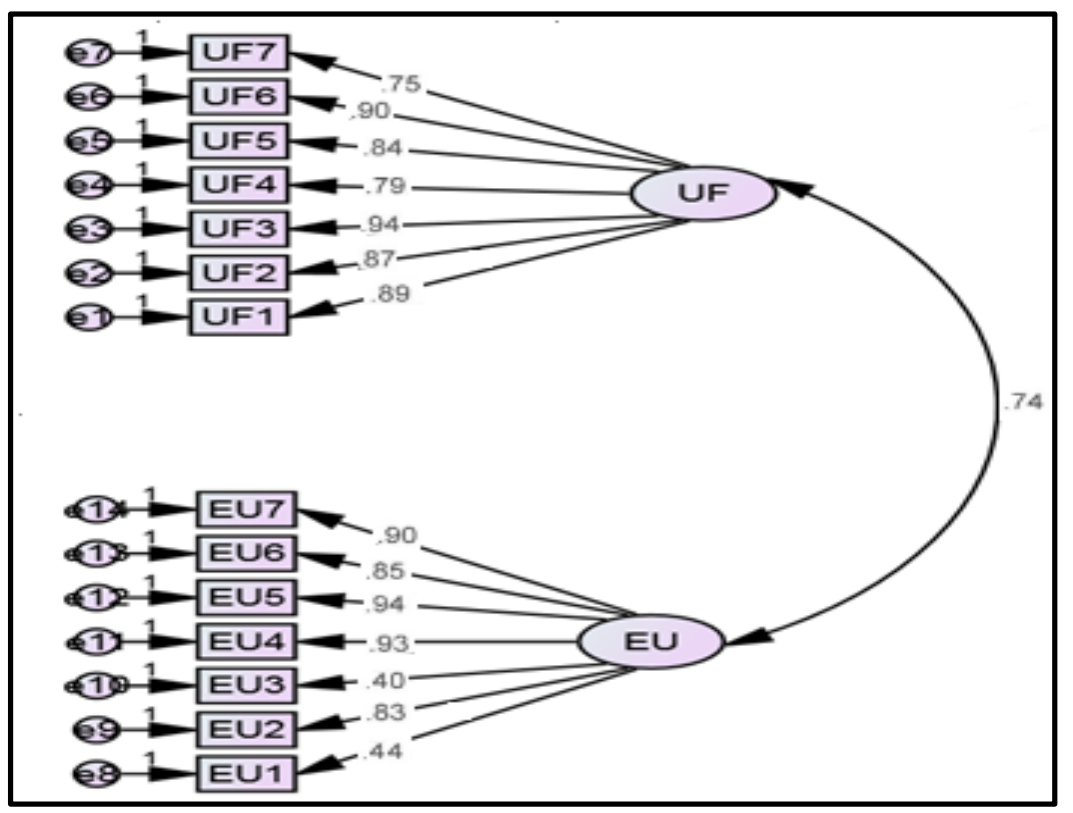

Fig. 7. CFA model of E-learning motivation

The above Figure 7 shows that significant relationships between the UF and EU (0.74) in the motivation of using the E-learning systems. In order to justify the motivation factors based on the respondents' opinions, the descriptive analysis is conducted (Figure 8). 


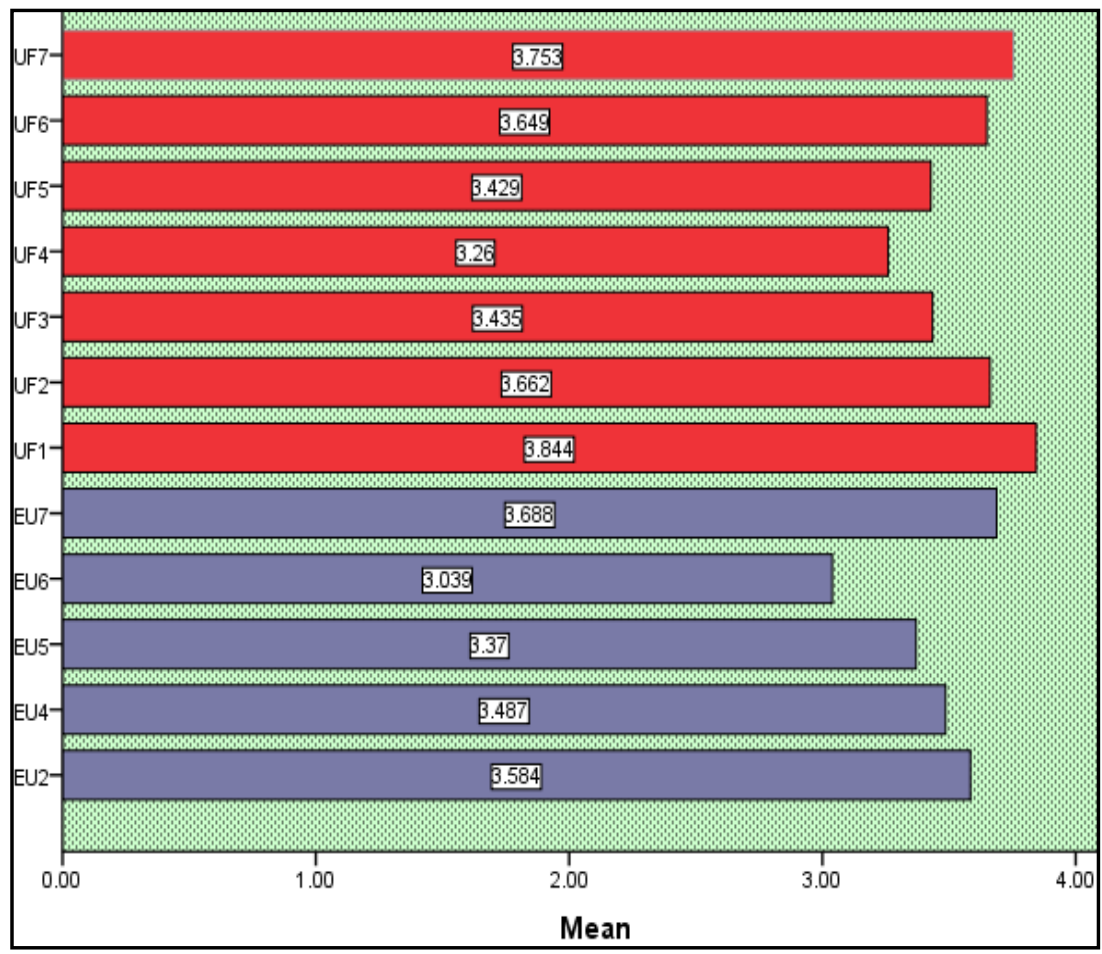

Fig. 8. Descriptive Analysis of E-learning Motivation

Based on the above Figure 8, the respondents are agreeing with some items in the usefulness of using the E-learning systems such as the E-leaning system is useful to learning (UF7), the using E-leaning system enhance my learning effectiveness (UF6), using E-leaning system gives greater control over the learning processes (UF2), and using E-leaning system improves the quality of learning processes (UF1). On the other hand, the respondents are neutral with UF3 (E-leaning system enable me to accomplish my learning tasks more quickly), UF4 (E-leaning system support critical aspects of my study), and UF5 (Using E-leaning system increase my learning productivity). Hence, the respondents are motivated to use the E-learning systems for additional learning tasks besides the traditional learning in the classrooms. The neutral opinions with many items may be related to the difficulties of the using of E-learning system. Later on the hypotheses testing based on SEM would clarify the relations between the various study factors.

Regarding to the EU factor, the respondents agree that it is easy to operate the Eleaning system for learning purposes (EU2). However, the respondents are neutral with the other items in this factor; it is easy to get the E-leaning system to do what I want to do (EU4), The E-leaning system is flexible to interact with (EU5), interacting with the E-leaning system requires low mental effort (EU6), and I Think the using of E-leaning system for learning is easy to use (EU7). It is clear that the interactivity of E-learning system make the respondents irresolute of the ease of use the E-learning 
systems. later on, the SEM model will discover the relationship between the Elearning difficulties and the ease of use the E-learning systems.

The CFA analyses are conducted on the third sub-model in this study, which is the students attitudes toward the using the E-learning systems. This model includes one factor called Attitudes (AT) of 4 items. As illustrates in Figure 9, all items in AT model are above the acceptable factors loading (>0.5). Thus, there is no need to exclude any item from this model. The reliability test of the AT records 0.93 , which is above the acceptable CA coefficient $(>0.7)$. The measurement indices show that the AT model is fit. The GFI coefficient is 0.884 , the cut value of the AGFI is 0.830 , the CFI coefficient 0.946 , the TLI coefficient is 0.968 , and the IFI coefficient 0.969 . The RMSEA test records 0.071 , which is acceptable coefficient that indicates the fitness among the model items. The results of all conducted tests are matched with the adequacy of X2/df (2.41), which is below the cut value of 5. Thus, the data of this model can be used usefully for further SEM analysis.

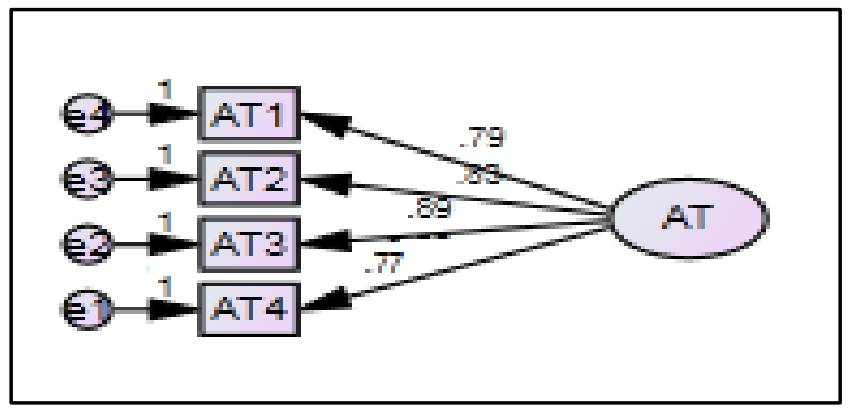

Fig. 9. CFA model for attitudes toward using the E-learning

In order to understand the attitudes toward the using of E-learning systems, the descriptive analysis is conducted on the four items in this model (Figure 10).

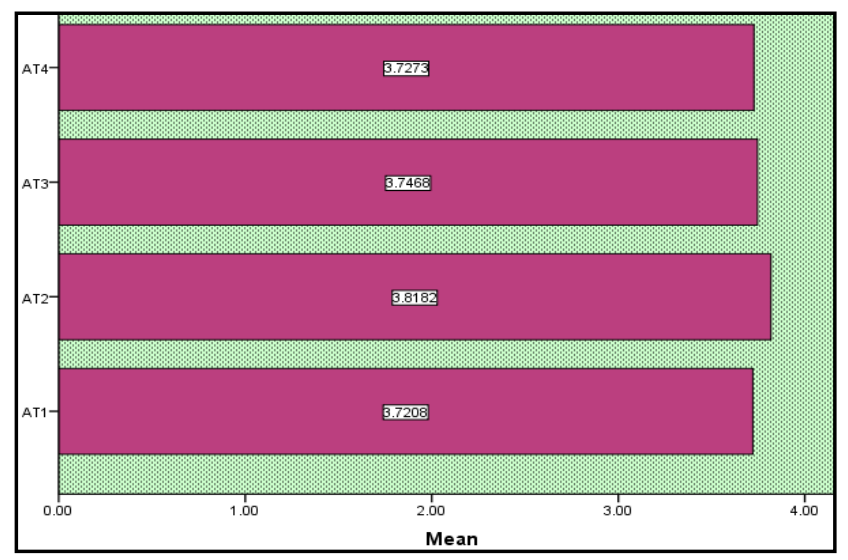

Fig. 10.Descriptive Analysis of E-learning Attitudes 
Based on the above Figure 10, the respondents are agreeing with all items in the attitudes model. The respondents intend to use the E-learning system in the future (AT1), intend to use the E-learning system as soon as possible (AT2), they will try to use more kinds of E-learning system (AT3), and they will strongly recommend others to use E-learning system (AT4). These results represent the positive attitudes toward the using of E-learning system by the students. However, the next section presents the SEM model and the hypotheses testing in order to discover the relationships between all factors in this study.

\subsection{Structural equation model and hypotheses testing}

In SEM statistical analysis, structural equation model is the second most important process. After validating the measurement model, the relationships between the variables can be assessed. The structural model provides specific details on the relationship between the independent or exogenous variables and dependent or endogenous variables. Firstly, it focus on the overall fit model, followed by the size, direction and significant of the hypothesized parameter estimates. This is shown in one-headed path diagram. The final stage involved confirmation of the structural model. This can be done by analyzing the proposed relationship between identified and assessed variables.

In order to conduct effective SEM test, the paths between the variables in the modified model are redraw. The retest of the correlation between the model items could improve the model fit through reduce the indirect or hidden relationship between the items i.e. enhance the $\mathrm{x} 2$ value. All CFA (factors loading, reliability, and fit indices) test for the final model provide accurate records. Hence, in this study is conducted depend on the entire 34 items in the modified model. Figure 11 illustrates the final SEM model, whereby the hypotheses could be tested.

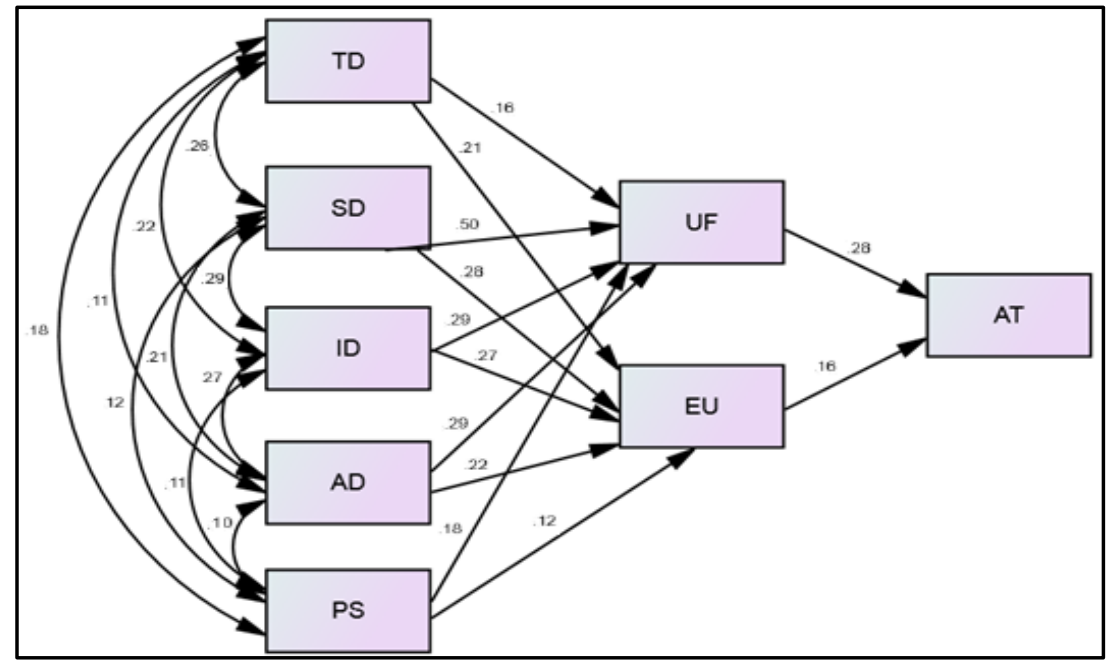

Fig. 11.SEM for Overall Model 
Based on the above Figure, the discussion of the three research hypotheses is as the following:

- H1 (+): The low difficulties in using the E-learning system have positive relation with the E-learning motivation.

Regarding to $\mathrm{H} 1$, the direct paths are tested between the E-learning difficulties and the motivation of using the E-learning systems. The direct path test is controlled by the $\mathrm{P}$-value between the variables. The relationship of $\mathrm{P}$-value that $<=0.05$ represent the supporting of the research hypotheses, while the P-value that $>0.05$ represent the rejection of the research hypotheses. In terms of relationship between the difficulties and motivation variables, the P-values are significant at the relationship between the ID and UF, ID and EU, SD and UF, SD and EU, AD and UF, and AD and EU. Thus, the $\mathrm{H} 1$ is mostly supported due to the major effects of the e-learning difficulties on the motivation of using the E-learning. Simply put, the students will motivated to use the E-learning systems that have low difficulties of technical, services, interactivity, and benefits. Otherwise, the students could refuse the using of the E-learning system in the university.

The result of $\mathrm{H} 1$ is supported by many studies that related to the motivation of using E-learning systems. The technical facilities should be owned or available for all students to motivate the using of E-learning systems [16, 17, 18, 19]. The students could be de-motivated of using the E-learning systems if they find that it is hard to own the technical requirements such as computer/mobile devices, internet connection, device capacity, and device processors.

On the other hand, the accessibility and availability of E-learning services are important variables in the motivation of using E-learning systems by the students [20, $21,22,23]$. the students need to benefit from the E-learning services in anytime and anywhere. The time and place limitation could de-motivate the using of E-learning systems.

Furthermore, the students should interactive with the features of E-learning systems in order to conduct the learning processes in an attractive manner $[16,17,18,19$, $20,24]$. Thus, the E-learning systems need to apply effective learning theories such as VARK in order to deliver the learning materials based on the student preferred learning styles. Using fixed learning style could de-motivate the using of E-learning systems by the students.

- H2 (+): The high level of E-learning motivation effect positively on students' attitudes toward the E-learning systems.

Regarding to $\mathrm{H} 2$, the direct paths are tested between the E-learning motivation and the attitude toward the using the E-learning systems. In terms of the relationship between these two factors, the P-values are significant at the relationship between the UF and AT (at p <0.05) and between the EU and AT (at p<0.01). Hence, the H2 is mostly supported due to the major effects of the e-learning motivation on the attitudes toward the using the E-learning. The students will provide positive attitude to use the 
E-learning systems when these systems are easy to use and useful in conduct the learning processes.

Several studies are agreed with the findings of $\mathrm{H} 2$ in this study [39, 40, 41]. There is extreme relationship between the E-learning motivation and attitudes toward the using of E-learning systems. The students who motivated to use the E-learning systems are usually providing positive attitudes toward the using of these systems. Otherwise, the students of low motivation in using the E-learning systems have negative attitudes toward the using of E-learning systems.

- H3 (+): There is positive relationship between the low difficulties in using the Elearning system and the attitudes toward the using of E-learning system through the mediating impact of the student's motivation.

In order to obtain significant mediation result, all three correlation variables i.e. path $\mathrm{a}, \mathrm{b}$, and $\mathrm{c}$ in the decision tree framework must be statistically significant. Even if one of these three variables is not significant, it is impossible to find significant mediation. If all three correlation variable i.e. path $\mathrm{a}, \mathrm{b}$, and $\mathrm{c}$ are significant, and if the direct effect of IV and DV is the multiple regression (i.e. path a') is not statistically significant, then the mediating variable will act as a full mediator. Otherwise, the mediation can be considered as partial mediation. The relationships between IV and DV will deem to be direct, indirect or no relationship if the analysis exhibit nonappearance of full or partial mediation.

Furthermore, when there is absence of significant effect in path "a" but with the presence of significant effects in path "b" and "c", the independent variable IV has non-significant indirect effect on dependent variable DV through mediating variable M. On the other hand, if the scenario in reversal where there is significant effect in path "a" but a none significant effect in path "b" and "c", the independent variable has only a direct effect on dependent variable. In another scenario where there is no significant effect in path "a" and absence of significant relationship in path "b" and c, then one can conclude that there would be no any relationship between IV and DV.

The indirect path test is applied to judge the H3; the P-value is 0.041 for the mediating effect of the E-learning motivation between the E-learning difficulties and the attitudes toward the using of E-learning systems. All of the E-learning motivation paths are provide significant results due to significant $\mathrm{P}$-value $(<0.05)$. Therefore, $\mathrm{H} 3$ considered as moderator. In other meaning, there is strong effect on the relationship between the E-learning difficulties and attitudes through the motivation factor. The difficulties of the E-learning system effects on the motivation of use these systems, and consequently, the attitudes will be affected.

There is lack in study the relationship between the E-learning difficulties and attitudes toward the using of E-learning systems through the mediating effect of the motivation of use E-learning system. However, there were many studies focused on the interrelation between the study variables [40, 42, 43, 44]. The researchers mentioned that it is important to understand the difficulties that face the students in using the Elearning systems. Without resolving these difficulties, the utilizing of E-learning fail could fail due to problems in students motivation of use the E-learning systems and problems in the attitudes toward these systems by the students. 


\section{Study Contribution}

In the universities, the adoption of E-leaning system could fail due to the weak understanding of the success keys of E-learning implementations. As discussed in this study, there are three important junctions support the applying of E-learning systems in the universities

- Avoid the difficulties of using the E-learning systems

- Improve the motivation of using the E-learning systems

- Assure the positive attitudes toward the using of E-learning systems

The connection between these three junctions is important to assure the success implementations of E-learning in the universities. The contribution of this study provides clear vision about the relationship between the E-learning difficulties and attitudes through the impact effect of the E-learning motivation.

The study results show the importance of avoiding several difficulties of E-learning systems in order to improve the students' motivation of using these systems. The students need to use E-learning system of low technical requirements i.e. low device speed, low device capacity, and low internet connection. On the other hand, the Elearning services should be provided in anytime and anywhere. Furthermore, the interactivity is another important difficulty that should be avoided. The students need high level of interactive communication with instructors via the E-learning system to simulate the real face to face communication. In addition, the students' awareness of the E-learning importance would be assured through valuable gained benefits such as the quality of E-leaning processes, and reduce the learning time and efforts in the university campus. Lastly, the E-learning security and privacy are not the main concerns in using the E-leaning systems by the students.

The study results show that the difficulties of using the E-learning systems could de-motivate the using of these systems. The various difficulties decrease the student believes in the usefulness and ease of use the E-learning systems. The De-motivation leads to negative attitudes toward the using the E-learning systems, whereby the adoption of these system could fail in universities. Based on the above discussion, the recommendations of this study are as the following:

- The synchronized E-learning approach is effective to provide effective communication between the instructors and the students. However, it is necessary to manage the learning discussion using efficient facilities. Usually, the instructors enable the E-learning communication from one side (i.e. the video and audio conversations with the students are disabled). Hence, the students need to provide their feedbacks in open conversation under good management of the conversation session.

- The students need to use the E-learning services (e.g. download/upload materials) in anytime and from anywhere. This requires availability and accessibility of Elearning server along the day hours.

- It is necessary to support low technology requirements of E-learning systems such as using low speed devices, low capacity devices, and low internet connection. In 
other meaning, the E-learning services should be designed based on low technology requirements.

- It is necessary to increase the awareness level of E-learning benefits through many procedures such as reduce the traditional learning hours and increase the E-learning hours, accomplish the assignments via e-learning systems, distribute the materials online using E-learning systems, and reduce the study days. These procedures will clarify to the students the gained benefits from E-learning implementations.

- Train the students on the using of E-learning facilities.

- Continual feedback collection from the students about their satisfaction of the using of E-learning systems.

\section{Conclusion and Future Works}

This study focuses on effects of motivations on the relationship between the difficulties and attitudes of using the E-learning systems by university students. The conceptual model is constructed based on standard TAM, and the study data were collected using questionnaire. The data were collected from 154 students in Ajloun University as a case study of Jordanian universities. Three research hypotheses are tested through the SEM analysis using AMOS tool. The analysis results show that there are many difficulties should be avoided to improve the motivation level of using the Elearning systems. The most important difficulties are the technical supporting, services accessibility and availability, system interactivity, and awareness of E-learning benefits. The difficulties of using the E-learning system could decrease the motivation of using these systems (usefulness and ease of use). The low motivation leads to negative attitudes toward the using of the E-learning system. Hence, the universities should adopt/adapt the most effective E-learning system of high interactivity facilities, low technical requirements, and ability to use the services from anywhere and in anytime. In the future, further studies will be conducted on various E-learning tools to compare between the facilities of these tools in the context of students motivation and attitudes.

\section{$7 \quad$ References}

[1] Rodríguez-Ardura, I., \& Meseguer-Artola, A. (2016). E-learning continuance: The impact of interactivity and the mediating role of imagery, presence and flow. Information \& Management, 53(4), 504-516. https://doi.org/10.1016/j.im.2015.11.005

[2] Goedegebuure, L. (2017). Australian university productivity; some food for thought. Improving service sector productivity: the economic imperative, 65 .

[3] Ramaiah, C. K. (2014). Emerging trends in electronic learning for library \& information science professionals. Knowledge, library and information networking, 328-350.

[4] Abubakar, B. M., \& Hassan, B. B. (2013). Strategies for developing an e-learning curriculum for library and information science (LIS) schools in the Muslim world: meeting the expectations in the digital age. International Journal of Humanities and Social Science, $3(1), 163-171$. 
[5] Lin, K. M. (2011). e-Learning continuance intention: Moderating effects of user e-learning experience. Computers \& Education, 56(2), 515-526. https://doi.org/10.101 6/j.compedu.2010.09.017

[6] Som, N. 2006. E-learning: a guidebook of principles, procedures and practices. 2nd Revised Edition, CEMCA.

[7] Arkorful, V., \& Abaidoo, N. (2015). The role of e-learning, advantages and disadvantages of its adoption in higher education. International Journal of Instructional Technology and Distance Learning, 12(1), 29-42.

[8] Almaiah, M. A., \& Almulhem, A. (2018). A conceptual framework for determining the success factors of e-learning system implementation using Delphi technique. Journal of Theoretical and Applied Information Technology, 96(17).

[9] Quadri, N. N., Muhammed, A., Sanober, S., Qureshi, M. R. N., \& Shah, A. (2017). Barriers effecting successful implementation of e-learning in Saudi Arabian universities. International Journal of Emerging Technologies in Learning (iJET), 12(06), 94-107. https://doi.org/10.3991/ijet.v12i06.7003

[10] Kew, S. N., Petsangsri, S., Ratanaolarn, T., \& Tasir, Z. (2018). Examining the motivation level of students in e-learning in higher education institution in Thailand: A case study. Education and Information Technologies, 23(6), 2947-2967. https://doi.org/10.10 07/s10639-018-9753-z

[11] Aqda, M. F., F. Hamidi \& F. Ghorbandordinejad 2011. The impact of constructivist and cognitive distance instructional design on the learner's creativity. Procedia computer science 3: 260-265. https://doi.org/10.1016/j.procs.2010.12.044

[12] Brown, T., Cosgriff, T., \& French, G. (2008). Learning style preferences of occupational therapy, physiotherapy and speech pathology students: a comparative study. Internet Journal of Allied Health Sciences and Practice, 6(3), 7.

[13] Davis, F.D. (1989). Perceived usefulness, perceived ease of use, and user acceptance of information technology. MIS Quarterly, 13(3), 319-340. https://doi.org/10.2307/249008

[14] Chuttur, M. 2009. Overview of the technology acceptance model: Origins, developments and future directions.

[15] Campbell, D. E., Wright, R., \& Clay, P. F. (2011). Deconstructing and operationalizing interactivity: an online advertising perspective. Journal of Information Technology Theory and Application (JITTA), 11(4), 3.

[16] Zhang, D., Zhou, L., Briggs, R. O., \& Nunamaker Jr, J. F. (2006). Instructional video in elearning: Assessing the impact of interactive video on learning effectiveness. Information \& management, 43(1), 15-27. https://doi.org/10.1016/j.im.2005.01.004

[17] Rasch, T., \& Schnotz, W. (2009). Interactive and non-interactive pictures in multimedia learning environments: Effects on learning outcomes and learning efficiency. Learning and Instruction, 19(5), 411-422. https://doi.org/10.1016/j.learninstruc.2009.02.008

[18] Lee, K. M., Jeong, E. J., Park, N., \& Ryu, S. (2011). Effects of interactivity in educational games: A mediating role of social presence on learning outcomes. Intl. Journal of HumanComputer Interaction, 27(7), 620-633. https://doi.org/10.1080/10447318.2011.555302

[19] Sun, J. N., \& Hsu, Y. C. (2011). An experimental study of learner perceptions of the interactivity of web-based instruction. Interacting with Computers, 24(1), 35-48. https://doi.org/10.1016/j.intcom.2011.11.001

[20] Peltier, J. W., Schibrowsky, J. A., \& Drago, W. (2007). The interdependence of the factors influencing the perceived quality of the online learning experience: A causal model. Journal of Marketing Education, 29(2), 140-153. https://doi.org/10.1177/0273475307302016

[21] Khan, A. I., Al-Shihi, H., Al-Khanjari, Z. A., \& Sarrab, M. (2015). Mobile Learning (MLearning) adoption in the Middle East: Lessons learned from the educationally advanced 
Paper-Motivation Path between the Difficulties and Attitudes of Using the E-Learning Systems in the ...

$\begin{array}{llll}\text { countries. } & \text { Telematics } & \text { and }\end{array}$ https://doi.org/10.1016/j.tele.2015.04.005

[22] Almaiah, M. A., Jalil, M. A., \& Man, M. (2016). Extending the TAM to examine the effects of quality features on mobile learning acceptance. Journal of Computers in Education, 3(4), 453-485. https://doi.org/10.1007/s40692-016-0074-1

[23] Humanante-Ramos, P. R., García-Peñalvo, F. J., \& Conde-González, M. Á. (2015). Personal learning environments and online classrooms: An experience with university students. IEEE Revista Iberoamericana de tecnologías del aprendizaje, 10(1), 26-32. https://doi.org/10.1109/rita.2015.2391411

[24] Mahle, M. (2007). Interactivity in distance education. Distance Learning, 4(1), 47.

[25] Lin, J. W., Huang, H. H., \& Chuang, Y. S. (2015). The impacts of network centrality and self-regulation on an e-learning environment with the support of social network awareness. British Journal of Educational Technology, 46(1), 32-44. https://doi.org/10. 1111/bjet. 12120

[26] Lin, J. W., \& Tsai, C. W. (2016). The impact of an online project-based learning environment with group awareness support on students with different self-regulation levels: An extended-period experiment. Computers \& Education, 99, 28-38. https://doi.org/10.10 16/j.compedu.2016.04.005

[27] Sabah, N. M. (2016). Exploring students' awareness and perceptions: Influencing factors and individual differences driving m-learning adoption. Computers in Human Behavior, 65, 522-533. https://doi.org/10.1016/j.chb.2016.09.009

[28] Anwar, M., \& Brusilovsky, P. (2017). Privacy and territoriality issues in an online social learning portal. International Journal of Information Security and Privacy (IJISP), 11(1), 1-17. https://doi.org/10.4018/ijisp.2017010101

[29] El-Masri, M., \& Tarhini, A. (2017). Factors affecting the adoption of e-learning systems in Qatar and USA: Extending the Unified Theory of Acceptance and Use of Technology 2 (UTAUT2). Educational Technology Research and Development, 65(3), 743-763. https://doi.org/10.1007/s11423-016-9508-8

[30] Ivanova, M., Grosseck, G., \& Holotescu, C. (2015, June). Researching data privacy models in eLearning. In 2015 International Conference on Information Technology Based Higher Education and Training (ITHET) (pp. 1-6). IEEE. https://doi.org/10.1 109/ithet.2015.7218033

[31] Qureshi, I. A., Ilyas, K., Yasmin, R., \& Whitty, M. (2012). Challenges of implementing elearning in a Pakistani university. Knowledge Management \& E-Learning, 4(3), 310.

[32] Yount, W. R. (2006). Research design and statistical analysis for Christian ministry.

[33] Ullman JB, Bentler PM (2003). IStructural Equation Modeling." In Handbook of Psychology. John Wiley \& Sons.

[34] Hair, J. F., Black, W. C., Babin, B. J., Anderson, R. E., \& Tatham, R. L. (2006). Multivariate data analysis (sixth Edition). United State of Amreica: Pearson prentice hall.

[35] Nunnally, J. C., and Bernstein, I. H. (1994). Psychometric theory (3rd ed.). New York: McGraw-Hill. ISBN 1847879500.

[36] Chau, P. Y., \& Hu, P. J. H. (2001). Information technology acceptance by individual professionals: A model comparison approach. Decision sciences, 32(4), 699-719. https://doi.org/10.1111/j.1540-5915.2001.tb00978.x

[37] Bagozzi, R. P., \& Yi, Y. (1988). On the evaluation of structural equation models. Journal of the academy of marketing science, 16(1), 74-94.

[38] Schumacker, R., \& Lomax, R. G. (2010). A beginner's guide to Structural Equation Modeling (Third ed.). New York: Routledge: Taylor \& Francis Group. ISBN 978-1-84169-8908 . 
[39] Hwang, G. J., Wu, P. H., Chen, C. C., \& Tu, N. T. (2016). Effects of an augmented realitybased educational game on students' learning achievements and attitudes in real-world observations. Interactive Learning Environments, 24(8), 1895-1906. https://doi.org/10.1 $\underline{080 / 10494820.2015 .1057747}$

[40] Shapiro, H. B., Lee, C. H., Roth, N. E. W., Li, K., Çetinkaya-Rundel, M., \& Canelas, D. A. (2017). Understanding the massive open online course (MOOC) student experience: An examination of attitudes, motivations, and barriers. Computers \& Education, 110, 35-50. https://doi.org/10.1016/j.compedu.2017.03.003

[41] Vandergoot, S., Sarris, A., Kirby, N., \& Ward, H. (2018). Exploring undergraduate students' attitudes towards interprofessional learning, motivation-to-learn, and perceived impact of learning conflict resolution skills. Journal of interprofessional care, 32(2), 211-219. https://doi.org/10.1080/13561820.2017.1383975

[42] Zhou, M., \& Teo, T. (2017). Exploring Student Voice in Teachers' Motivation to Use ICT in Higher Education: Qualitative Evidence from a Developing Country. International Journal of Educational Technology, 4(1), 26-33.

[43] Alhazbi, S. (2016). Active blended learning to improve students' motivation in computer programming courses: A case study. In Advances in engineering education in the Middle East and North Africa (pp. 187-204). Springer, Cham. https://doi.org/10.1007/978-3-31915323-0_8

[44] Bai, H., Aman, A., Xu, Y., Orlovskaya, N., \& Zhou, M. (2016). Effects of Web-Based Interactive Modules on Engineering Students' Learning Motivations. American Journal of Engineering Education, 7(2), 83-96. https://doi.org/10.19030/ajee.v7i2.9840

\section{Authors}

Ghazi Shakah is an Information Technology Faculty from Ajloun National University (ANU), Ajloun, Jordan

Ali. T. Al-Oqaily works for Ajloun National University (ANU) as an Information Technology Faculty, in Ajloun city, Jordan. Email: oqili83@yahoo.com

Dr. Fadi Alqudah is a Management Faculty from Ajloun National University (ANU) situated in Ajloun, Jordan. Email : dr.fadiqudah@yahoo.com

Article submitted 2019-03-23. Resubmitted 2019-07-01. Final acceptance 2019-07-01. Final version published as submitted by the authors. 